\title{
Acceptance and Efficacy of a Guided Internet Self-Help Treatment Pro- gram for Obese Patients with Binge Eating Disorder
}

\author{
Carrard Isabelle ${ }^{1, *}$, Crépin Christelle ${ }^{1}$, Rouget Patrick $^{2}$, Lam Tony $^{3}$, Van der Linden Martial ${ }^{4}$ \\ and Golay Alain ${ }^{1}$
}

\author{
${ }^{1}$ Service of Therapeutic Education for Chronic Diseases, University Hospitals of Geneva, Geneva, Switzerland \\ ${ }^{2}$ Service of Liaison psychiatry, University Hospitals of Geneva, Geneva, Switzerland \\ ${ }^{3}$ Netunion, Lausanne, Switzerland \\ ${ }^{4}$ Faculty of Psychology and Educational Sciences, University of Geneva, Geneva, Switzerland
}

\begin{abstract}
Introduction: A significant percentage of obese patients suffer from binge eating disorder (BED), with negative consequences on psychological health, quality of life, weight loss treatment and maintenance. Cognitive behavioral therapy (CBT), delivered in traditional or self-help format, is effective in reducing BED symptoms. To improve dissemination, a self-help treatment program composed of eleven CBT based modules was implemented on the Internet and evaluated in a population of adult obese patients with BED.

Method: Forty-two obese BED patients wait-listed for a multi-disciplinary obesity treatment took part in the study. Twenty-two patients completing the six-month online guided self-help treatment program were compared to a control group of twenty patients without intervention. Both groups were evaluated before and after six months of Internet selfhelp treatment or waiting list. A follow-up evaluation was carried out six months later.

Results: Participants in the online self-help treatment program showed higher binge eating abstinence rates, lower EDE-Q shape and weight concerns, and improved TFEQ disinhibition of eating and hunger scores compared to the control group. They also scored better on psychological health and quality of life measures after intervention, and gains were maintained at follow-up. No effect was found regarding BMI. The number of modules completed was correlated with a better quality of life improvement at post evaluation. Participants rated the program as useful and easy to use.
\end{abstract}

Conclusion: The Internet seems to be a valuable tool for disseminating CBT for BED obese patients. Acceptance of new technology was good in this population. Further research is needed with a larger sample to corroborate these results.

Keywords: Internet, binge eating disorder, obesity, cognitive behavioral therapy, self-help treatment.

\section{INTRODUCTION}

Obesity is now recognized as a chronic illness with severe and adverse impact on health and longevity [1]. Obesity is often associated with psychiatric distress, such as higher incidence of depression, negative body image, disordered eating, and impaired quality of life [2]. Its management should be considered as a long-term process [3].

Binge Eating Disorders (BED) is the most common eating disorder seen in overweight and obesity. BED was included as a provisional diagnosis in DSM-IV [4]. This disorder is characterized by recurrent episodes of binge eating with loss of control in the absence of compensatory behaviors. BED is closely related to overweight and obesity. The observed prevalence in obese individuals seeking weight loss treatment reached $30 \%$ to $50 \%[5,6]$. Obese people with

\footnotetext{
*Address correspondence to this author at the Service of Therapeutic Education for Chronic Diseases, Department of Community Medicine, Geneva University Hospitals, Gabrielle-Perret-Gentil 4, CH-1211 Geneva 14, Switzerland; Tel: +41.22.372.97.01; Fax: +41.22.372.97.10;

E-mail: isabelle.carrard@hcuge.ch
}

BED differ significantly from obese people without BED and show more psychological disturbances, such as lower self-esteem, lower self-efficacy, difficulties in accurately identifying emotions and other internal states, and higher levels of impulsivity [7]. They exhibit higher lifetime rates of affective disorder [8] and a lower quality of life [9, 10]. BED obese individuals undergoing weight loss treatment lose less weight than obese patients without BED [11]. Taken together, these factors support the systematic screening of BED in people seeking a treatment for obesity [6].

The utility and validity of BED diagnosis is now recognized in the eating disorders area $[12,13]$. Current diagnostic criteria include, notably, the consumption of a "large" amount of food and a binge eating episodes frequency of at least two days a week for the last six months. Some ongoing discussions question the importance of using binge size and frequency for setting the diagnostic threshold $[14,15]$. The loss of control and the distress it causes seem to be the most salient aspects of binge eating. A large number of studies suggested that subthreshold BED patients have comparable risk of psychiatric distress as women with full syndrome BED and deserve similar treatment $[16,17]$. 
A review of several treatment studies suggested that Cognitive Behavioral Therapy (CBT) for BED was effective in reducing the number of binge episodes and in improving related factors such as restraint, disinhibition and hunger [18]. CBT treatment, delivered as guided or pure self-help interventions, also proved efficacious in the treatment of BED [19]. CBT guided self-help treatment showed better remission rates compared to behavioral weight loss treatment and control conditions [20].

Self-help methods were developed to provide treatment on a larger scale. With the increased development of new technologies, the Internet has become a promising tool to deliver interventions for promoting healthy lifestyle and behaviors [21]. Self-help techniques were transferred to the Internet to improve treatment access, especially for overcoming practical constraints such as cost, time and distance. A review of online approaches indicated a reduction of risk factors and an improvement of symptoms across a broad spectrum of mental illness and related conditions: depression, stress, insomnia, headache or eating disorders [22]. In the field of obesity, online behavioral programs focusing on weight loss and weight loss maintenance were also introduced. A first randomized controlled trial compared an online 6-month structured behavioral weight loss program with a weight loss education website [23]. The behavior therapy group lost more weight than the education group after three and six months. Efficacy was better with weekly therapist contact via e-mail [24]. The importance of human counseling in enhancing outcomes of online treatment programs was highlighted [25]. Synchronous communication, interactivity and frequent updates were also noted as factors improving adherence [26]. The Internet and e-mail appear to be viable methods for the delivery of structured behavioral weight loss or weight maintenance programs [27].

However, these weight loss programs have mainly focused on behavior modification but have not addressed characteristic psychological aspects of binge eating. Only a single recent randomized controlled study evaluated an Internet intervention to reduce binge eating and overweight in adolescents [28]. This 16-week Internet program with cognitivebehavioral principles for BED, weight loss intervention and hunger and satiety awareness skills, had a significant effect on binge eating and weight maintenance simultaneously.

For eating disorders, significant research on online delivery of CBT based self-help treatment programs has been conducted with bulimia nervosa [29-33], showing that binge eating and related psychopathology can be improved with the use of Internet programs. BED entails many adverse consequences and the Internet has a real potential for dissemination of information and treatment for BED patients who are still under-treated [34]. The goal of this study was to evaluate an Internet CBT-based self-help treatment program (hereinafter: Internet program) specifically designed for BED treatment, used with guidance of a psychologist, in a population of BED obese patients. The Internet program was dedicated to psychological aspects of BED, without directly tackling weight loss. Hypotheses were that eating disorders would decrease in the Internet program group compared to a control group, and that psychological health and quality of life would improve. It was also posited that these improve- ments would be sustained after all patients had undertaken weight loss treatment.

\section{METHOD}

\section{Participants}

\section{Recruitment}

Forty-two patients were recruited from November 2007 to January 2009 from the University Hospitals of Geneva (Switzerland) adult obesity program, a two year multidisciplinary weight loss treatment (Weight Loss Treatment: hereinafter WLT). The WLT has an average waiting list of six months. The Internet program was offered to wait-listed participants during information sessions for the WLT. It was emphasized that the Internet program was experimental and specifically designed for people with eating disorders. It did not replace WLT but could be seen as a complement for people with BED. Eight information sessions took place during the recruitment period. The Internet program was proposed in four of them. People attending the four other sessions were contacted to be evaluated as a control group. This was a controlled study without randomization.

\section{Inclusion Criteria}

Participants included were women, aged from 20 to 70 , with a BMI between 30 and 50. Eating disorders criteria were binge eating episodes, with an emphasis on loss of control. Binge size was not disqualifying and people reporting mainly binges on normal quantity of food were included. Frequency had to be at least once a month during the last three months. BED diagnosis was established according to DSM-IV criteria. Participants had to speak French fluently and had to have adequate skills in the use of Internet.

\section{Procedure}

Participants were assessed during three evaluation sessions. Baseline evaluation took place at the time of participants' registration for WLT, after acceptance of either Internet program or participation in the control group. Participants all gave their written informed consent. Both Internet program and control groups lasted six months and post evaluation took place at the end, just before WLT began. A follow-up evaluation was carried out six months after WLT began. The protocol was approved by the local ethical committee (number 07-167).

\section{Internet Program Condition}

The Internet program was written by I.C. and P.R. It referred to CBT main principles for binge eating treatment, described e.g. in the self-help book Overcoming binge eating [35]. It specifically focused on the eating disorder rather than on weight loss and consisted of eleven modules including lessons on motivation, daily self-monitoring, binge triggers, meal plans, strategies to prevent binges, physical activity, problem-solving, assertiveness, automatic thoughts, cognitive restructuring and relapse prevention. Each module encompassed theory and exercises to encourage participants to apply the techniques in their everyday life. A self-monitoring diary had to be completed during the whole course of the program. Diary records included number of meals and binges, binge triggers, pleasure derived from eating, physical activity or strategies used to prevent binges. Two fictitious 
characters named Beverly and Scott illustrated all exercises and techniques. They showed how to complete exercises and explained their difficulties, giving concrete examples to participants.

Participants went through the modules sequentially. First and last modules could be completed quickly; others lasted a minimum of two weeks before participants could gain access to the next module. Participants had six months to complete the Internet program.

Self-monitoring was supported by automatic feedback using charts providing an objective view of frequency and change of participants' eating behavior. Two audio exercises were included. First, a raisin exercise inspired by mindfulness techniques was used as a real-life situation to experiment with sensations while eating a raisin deliberately slowly and concentrating on vision, touch, hearing and taste. Second, a classical progressive muscle relaxation exercise was carried out using the Jacobson technique [36].

The Internet program was used with the guidance of a psychologist, who acted as a coach. Participants met their coach during assessment. Each week participants had to write at least one e-mail to their coach who answered once a week. Coaches provided support and answered questions. They could access all exercises completed by participants to monitor their progress. Coaches explained the CBT program rationale to ensure the correct use of the techniques. Psychotherapy was not provided via e-mail. If participants did not enter the Internet program or did not write any e-mail for two weeks, their coach called them on the phone to rebuild their motivation. After four weeks without any connection, the participants' program access was cancelled and they were considered as a study dropout.

Scrupulous attention was given to security and data protection. Participants received a pseudonym and a password to access the Internet program. All personal patient information was stored separately under lock and key. Emails were encrypted and exchanged via a secured messaging module. The website met Health on the Net (HON) quality and ethics standards.

\section{Control Group}

Patients in the control group had to wait for WLT on the standard waiting list for six months and were not contacted during that time. They were informed about the Internet program at their first evaluation and were told that they could benefit from it after the study was completed.

\section{Measures}

Patients were assessed on dimensions known to be more severe for BED obese patients, such as eating disorder symptoms, depression and psychological health, as well as quality of life.

\section{Eating Disorder Symptoms}

Three measures were used to describe eating disorder symptoms:

- EDO: Eating Disorders in Obesity [37]. This short self-report questionnaire is based on DSM-IV diagnostic criteria for BED, with questions excluding bulimia nervosa. It was translated from English to
French for this study [38], back-translated and approved by the author. The EDO was used as a structured interview to ensure a good understanding of questions and definitions. Screening of symptoms is assessed on responses dating from the previous three and six months.

- EDE-Q: Eating Disorder Examination-Questionnaire [39, 40], self-report questionnaire which comprises four subscales - restraint, eating concern, shape concern and weight concern - and a total score, as well as symptom frequency. Assessment is based on the past 28 days. The number of objective binge days was used in this study as well as the four subscales and the total score.

- TFEQ: Three-Factor Eating Questionnaire [41, 42], 51-item inventory, which was designed to measure cognitive restraint, the tendency towards disinhibition of eating or loss of control of eating, and susceptibility to hunger (i.e. perception of hunger and satiety).

The EDE-Q and the TFEQ are widely used instruments for assessing BED and obese patients [43, 44].

\section{Psychological Health}

Two questionnaires were used:

- BDI-II: Beck Depression Inventory-II [45], 21-item self-report inventory of depressive symptoms. The total scores range from 0 to 63 , a higher score indicating more severe depression.

- SCL-90R: Symptom Checklist-90-Revised [46, 47], 90-item self-report instrument to assess a broad range of psychopathological symptoms. A total score can be computed to obtain the Global Severity Index (GSI), an indicator of overall psychological distress.

\section{Quality of Life}

One scale was chosen from all the questionnaires measuring quality of life, because it was developed to assess quality of life in obesity in particular:

- IWQOL-Lite: Impact of Weight on Quality of Life short form [48, 49], 31-item self-report questionnaire assessing five domains - physical function, selfesteem, sexual life, public distress and work - plus a total score. Scoring in this paper is based on transformed scores ranging from 0 to 100 . The higher the score, the better the quality of life.

\section{Interest, Satisfaction, Compliance}

In addition to these standardized instruments, data on socio-demographic facts and patient history were collected, as well as an evaluation of participants' interest in the study and satisfaction with the Internet program. Satisfaction ratings were made on the ease and usefulness of the Internet program, with scales from 0 (not satisfying) to 10 (very satisfying). Data for compliance analyses were extracted from the database, such as number of days the self-monitoring diary was completed, number of messages sent, and number of modules completed at the time of post evaluation or time spent in each module. 


\section{Data Analyses}

Data were analysed with SPSS for Windows, version 15.0, 2006 (SPSS Inc, Chicago, IL).

Data were screened for normality. All data were approximately normally distributed, allowing the use of parametric analyses. Dropouts were excluded from the longitudinal analyses.

Baseline comparisons between the two groups were calculated with independent samples t-tests and chi-squares for categorical variables.

To compare outcome between the Internet program group and the control group, ANCOVAs were performed with post assessment scores as dependent variables and baseline scores as covariates. To evaluate a sustained effect of Internet program after six months of WLT, ANCOVAs were performed with follow-up assessment scores as dependent variables and baseline scores as covariates. Effect sizes used were partial eta squares, reporting the proportion of variance explained by a factor after control of baseline values. Guidelines of $0.01,0.06$, and 0.14 as small, medium, and large effect sizes respectively were applied [50]. Chi-squares were calculated

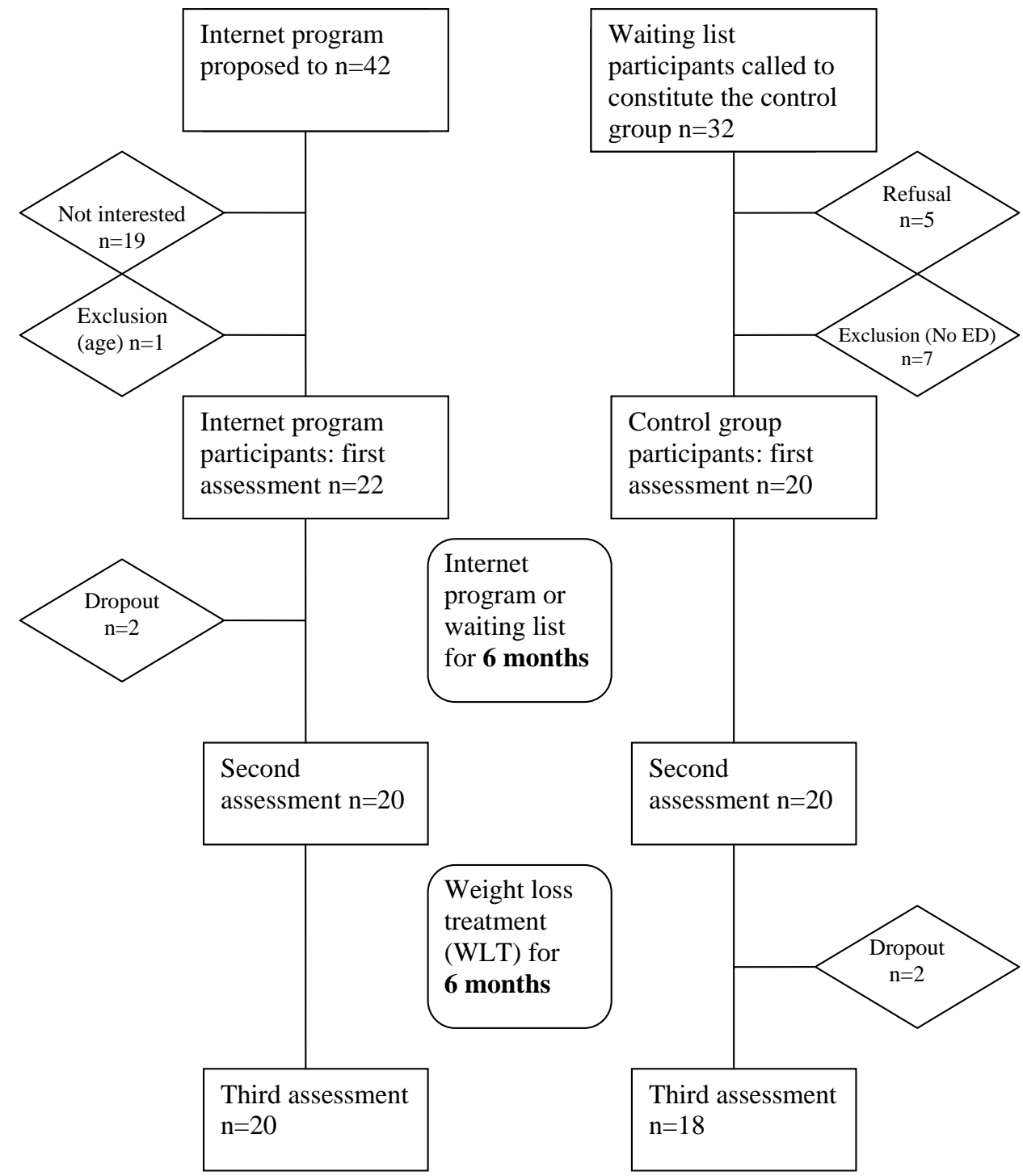

to analyse differences between percentages of binge eating abstinence at post and follow-up evaluations.

A few compliance indicators were theoretically selected and a multiple regression analysis was run to evaluate whether compliance with any aspects of the Internet program predicted the improvement of quality of life evaluated by the difference between post and baseline scores of IWQOL-Lite total score. IWQOL-Lite total score baseline value was introduced in the regression as covariate.

\section{RESULTS}

\section{Participant Flow Through the Study}

The flow of participants through the study is described in Fig. (1).

The opportunity to try the Internet program was offered to 42 patients enrolling in WLT. Twenty-three people (55\%) were interested in trying the Internet program. One individual was excluded because of age (74 years old) and 22 began the Internet program. Two participants $(9 \%)$ dropped out during the course of the program. Twenty participants were evaluated at second and third assessments. 
Thirty-two individuals were contacted to participate in the control group. Five patients refused to take part in the study; seven were not eligible because they did not display any eating disorder symptoms. Twenty patients were assessed at baseline and after six months of waiting list. Two people withdrew from the research during the first six months of WLT, resulting in a final sample of 18 patients that completed the three evaluation sessions.

\section{Baseline}

At first evaluation, participants in the Internet program group were aged from 21 to 70 years with a BMI from 30 to 50. Participants in the control group were aged from 24 to 52 years with a BMI from 30 to 46 . Sixty-three percent of participants were married; fifty-five percent had a professional training and the rest had an academic background. Seventy percent of participants were working at the time of the study.

Full diagnostic criteria for BED were met by $54.5 \%$ $(n=12)$ of participants in the Internet program group and 45 $\%(\mathrm{n}=9)$ of participants in the control group. Twenty-one participants were considered as subthreshold: 11 participants reported loss of control with a "normal" quantity of food (Internet program group $\mathrm{n}=4$; control group $\mathrm{n}=7$ ) and 10 participants described binge eating episode frequency of less than two days per week over the last six months (Internet program group $=6$ and control group $=4$ ).

Baseline values were compared between both groups with independent samples t-tests or chi-squares for categorical variables. Means and frequencies displayed in Table 1 were similar between groups.

\section{Treatment Outcome}

Percentages of patients with or without eating disorders were calculated at post and follow-up evaluations. Eating disorder criterion was the presence of at least one binge episode over the last three months. Fig. 2 shows that the binge eating abstinence rate was superior for patients in the Internet program group compared to the control group at post evaluation. Forty-five percent $(n=9)$ of patients in the Internet program group were abstinent at post evaluation, compared to $15 \%(n=3)$ in the control group (Pearson's chisquare $=4.3, \mathrm{p}<.05)$. Among the nine abstinent individuals in

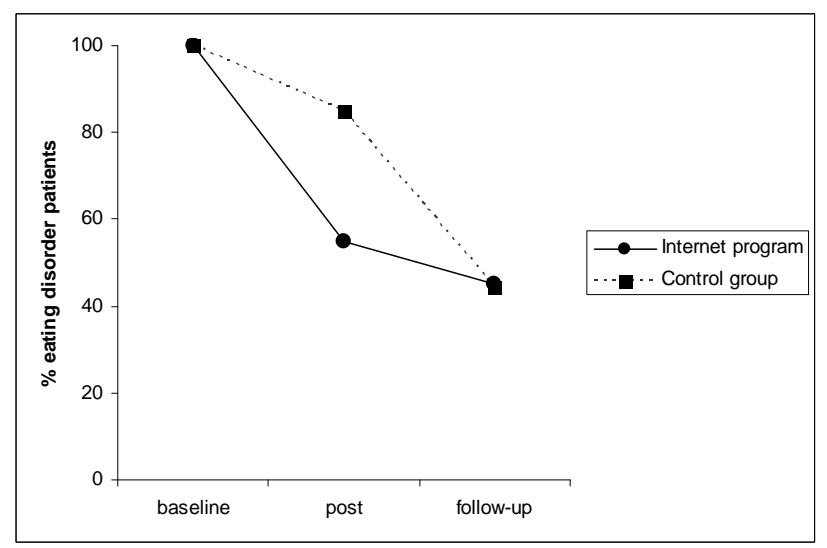

Fig. (2). Percentages of patients with eating disorders at baseline, after Internet program or waiting list (post) and after six months of WLT (follow-up).
Table 1. Baseline Patients' Characteristics in the Two Groups

\begin{tabular}{|c|c|c|}
\hline & $\begin{array}{l}\text { Internet group } \\
\quad(\mathrm{n}=22)\end{array}$ & $\begin{array}{c}\text { Control group } \\
(\mathrm{n}=20)\end{array}$ \\
\hline Age (years) & $44.6(11.4)$ & $41.0(8.2)$ \\
\hline $\operatorname{BMI}\left(\mathrm{kg} / \mathrm{m}^{2}\right)$ & $35.9(4.9)$ & $36.4(4.4)$ \\
\hline Weight $(\mathrm{kg})$ & $95.6(19.1)$ & $98.2(15.6)$ \\
\hline Full BED diagnostic & $54.5 \%$ & $45.0 \%$ \\
\hline Married & $54.5 \%$ & $70.0 \%$ \\
\hline Professional training & $50.0 \%$ & $60.0 \%$ \\
\hline Professional activity & $77.3 \%$ & $60.0 \%$ \\
\hline EDE-Q objective binge days & $10.2(8.4)$ & $7.6(9.6)$ \\
\hline EDE-Q Restraint & $1.6(1.1)$ & $1.9(1.4)$ \\
\hline EDE-Q Eating concern & $2.2(1.7)$ & $2.5(1.7)$ \\
\hline EDE-Q Shape concern & $4.3(0.7)$ & $4.3(1.1)$ \\
\hline EDE-Q Weight concern & $4.1(0.9)$ & $3.6(1.1)$ \\
\hline EDE-Q total score & $3.0(0.7)$ & $3.1(1.0)$ \\
\hline TFEQ Restraint & $7.7(5.0)$ & $8.7(4.2)$ \\
\hline TFEQ Disinhibition & $11.6(2.4)$ & $11.6(2.5)$ \\
\hline TFEQ Hunger & $7.2(2.9)$ & $8.2(3.2)$ \\
\hline BDI-II & $11.2(9.7)$ & $15.0(11.5)$ \\
\hline SCL-90R GSI & $0.7(0.4)$ & $0.8(0.6)$ \\
\hline IWQOL physical function & $54.3(24.3)$ & $53.6(24.6)$ \\
\hline IWQOL self-esteem & $34.2(23.9)$ & $34.9(22.5)$ \\
\hline IWQOL sexual life & $70.0(31.3)$ & $62.5(35.1)$ \\
\hline IWQOL public distress & $82.7(15.4)$ & $79.0(21.4)$ \\
\hline IWQOL work & $85.1(17.2)$ & $76.8(22.8)$ \\
\hline IWQOL total score & $60.1(16.7)$ & $57.5(20.0)$ \\
\hline
\end{tabular}

Note: BMI Body Mass Index; BED Binge Eating Disorder; EDE-Q Eating Disorder Examination-Questionnaire; TFEQ Three-Factor Eating Questionnaire; BDI-II Beck Depression Inventory; SCL-90R GSI: Symptom Checklist-90-Revised Global Severity Index; IWQOL: Impact of Weight on Quality of Life; Means (SD) or frequencies

the Internet program group, four met subthreshold and five met full BED criteria at baseline. In the control group, the three abstinent persons met subthreshold BED criteria at baseline.

At follow-up evaluation, after six months of WLT, both groups reached the same result, with $55 \%$ abstinence in each group (Pearson's chi-square $=0.001, \mathrm{~ns}$ ).

After six months of the Internet program, participants' shape concern $(\mathrm{F}(2,37)=4.5, \mathrm{p}=.042)$ measured by EDE-Q, as well as perception of hunger $(\mathrm{F}(2,37)=5.2, \mathrm{p}=.028)$ measured by TFEQ, significantly improved compared to the control group (Table 2). Weight concern $(\mathrm{F}(2,37)=3.4, \mathrm{p}=.073)$ and disinhibition $(\mathrm{F}(2,37)=3.4, \mathrm{p}=.075)$ differences approached but did not reach significance. Effects sizes for 
Table 2. Eating Disorder Dimensions for the Internet Program and Control Groups at Baseline, Post and Follow-up Evaluations; p-values, Effect Sizes and Confidence Intervals for Differences between Groups

\begin{tabular}{|c|c|c|c|c|c|c|c|c|c|c|c|c|}
\hline & \multicolumn{2}{|c|}{ Baseline assessment } & \multicolumn{2}{|c|}{ Post assessment } & \multicolumn{2}{|c|}{$\begin{array}{c}\text { Follow-up assess- } \\
\text { ment }\end{array}$} & \multicolumn{3}{|c|}{ Post Differences } & \multicolumn{3}{|c|}{ Follow-up Differences } \\
\hline & $\begin{array}{c}\text { Internet } \\
\mathrm{n}=22\end{array}$ & $\begin{array}{c}\text { Control } \\
n=20\end{array}$ & $\begin{array}{c}\text { Internet } \\
\mathrm{n}=20\end{array}$ & $\begin{array}{c}\text { Control } \\
\mathrm{n}=20\end{array}$ & $\begin{array}{c}\text { Internet } \\
\mathrm{n}=20\end{array}$ & $\begin{array}{c}\text { Control } \\
\mathrm{n}=18\end{array}$ & $\begin{array}{c}\mathrm{p}- \\
\text { value }\end{array}$ & $\mathrm{ES}^{\mathrm{a}}$ & CI (95\%) & $\mathrm{p}$-value & $\mathrm{ES}^{\mathrm{b}}$ & $\begin{array}{c}\text { CI } \\
(95 \%)\end{array}$ \\
\hline $\begin{array}{l}\text { EDE-Q objec- } \\
\text { tive binge days }\end{array}$ & $\begin{array}{l}10.2 \\
(8.4)\end{array}$ & $7.6(9.6)$ & $3.4(4.9)$ & $\begin{array}{c}4.9 \\
(8.9)\end{array}$ & $2.3(3.7)$ & $\begin{array}{c}4.4 \\
(8.7)\end{array}$ & .308 & 0.028 & $-6.86 ; 2.23$ & .251 & 0.037 & $\begin{array}{c}-7.02 \\
1.90\end{array}$ \\
\hline $\begin{array}{l}\text { EDE-Q Re- } \\
\text { straint }\end{array}$ & $\begin{array}{c}1.6 \\
(1.1)\end{array}$ & $1.9(1.4)$ & $1.9(1.3)$ & $\begin{array}{c}1.6 \\
(1.1)\end{array}$ & $1.6(1.5)$ & $\begin{array}{c}1.3 \\
(1.5)\end{array}$ & .304 & 0.028 & $-0.34 ; 1.06$ & .247 & 0.038 & $\begin{array}{c}-0.37 \\
1.39\end{array}$ \\
\hline $\begin{array}{l}\text { EDE-Q Eating } \\
\text { concern }\end{array}$ & $\begin{array}{c}2.2 \\
(1.7) \\
\end{array}$ & $2.5(1.7)$ & $1.0(1.0)$ & $\begin{array}{l}1.5 \\
(1.4) \\
\end{array}$ & $0.8(0.9)$ & $\begin{array}{c}0.9 \\
(1.3) \\
\end{array}$ & .282 & 0.031 & $-1.05 ; 0.31$ & .979 & 0.000 & $\begin{array}{c}-0.72 \\
0.71\end{array}$ \\
\hline $\begin{array}{l}\text { EDE-Q Shape } \\
\text { concern }\end{array}$ & $\begin{array}{c}4.3 \\
(0.7)\end{array}$ & $4.3(1.1)$ & $3.2(1.2)$ & $\begin{array}{c}3.9 \\
(1.1)\end{array}$ & $2.7(1.4)$ & $\begin{array}{c}3.1 \\
(1.8)\end{array}$ & .042 & 0.107 & $\begin{array}{l}-1.26 \\
-0.03\end{array}$ & .133 & 0.063 & $\begin{array}{c}-1.48 \\
0.20\end{array}$ \\
\hline $\begin{array}{l}\text { EDE-Q Weight } \\
\text { concern }\end{array}$ & $\begin{array}{c}4.1 \\
(0.9) \\
\end{array}$ & $3.6(1.1)$ & $3.0(0.9)$ & $\begin{array}{c}3.2 \\
(1.2) \\
\end{array}$ & $2.4(1.0)$ & $\begin{array}{c}2.7 \\
(1.7) \\
\end{array}$ & .073 & 0.084 & $-1.01 ; 0.05$ & .166 & 0.054 & $\begin{array}{c}-1.47 \\
0.26\end{array}$ \\
\hline $\begin{array}{l}\text { EDE-Q total } \\
\text { score }\end{array}$ & $\begin{array}{c}3.0 \\
(0.7)\end{array}$ & $3.1(1.0)$ & $2.3(0.9)$ & $\begin{array}{c}2.6 \\
(0.9)\end{array}$ & $1.9(1.0)$ & $\begin{array}{c}2.1 \\
(1.2)\end{array}$ & .290 & 0.030 & $-0.62 ; 0.19$ & .669 & 0.005 & $\begin{array}{c}-0.78 \\
0.50\end{array}$ \\
\hline TFEQ Restraint & $\begin{array}{c}7.7 \\
(5.0) \\
\end{array}$ & $8.7(4.2)$ & $9.5(5.1)$ & $\begin{array}{c}9.4 \\
(4.4) \\
\end{array}$ & $8.9(4.5)$ & $\begin{array}{c}8.3 \\
(4.0) \\
\end{array}$ & .621 & 0.007 & $-1.58 ; 2.60$ & .376 & 0.022 & $\begin{array}{c}-1.03 \\
2.67\end{array}$ \\
\hline $\begin{array}{l}\text { TFEQ Disin- } \\
\text { hibition }\end{array}$ & $\begin{array}{l}11.6 \\
(2.4)\end{array}$ & $11.6(2.5)$ & $9.8(3.2)$ & $\begin{array}{l}11.0 \\
(2.8)\end{array}$ & $8.4(3.5)$ & $\begin{array}{c}9.5 \\
(3.6)\end{array}$ & .075 & 0.083 & $-2.98 ; 0.15$ & .246 & 0.038 & $\begin{array}{c}-3.13 \\
0.83\end{array}$ \\
\hline TFEQ Hunger & $\begin{array}{c}7.2 \\
(2.9)\end{array}$ & $8.2(3.2)$ & $5.4(3.4)$ & $\begin{array}{l}8.0 \\
(3.7)\end{array}$ & $3.9(3.1)$ & $\begin{array}{c}6.1 \\
(3.9)\end{array}$ & .028 & 0.123 & $\begin{array}{l}-3.84 \\
-0.23\end{array}$ & .060 & 0.097 & $\begin{array}{c}-3.68 \\
0.08\end{array}$ \\
\hline BMI & $\begin{array}{l}35.9 \\
(4.9)\end{array}$ & $36.4(4.4)$ & $34.5(4.7)$ & $\begin{array}{l}36.2 \\
(4.6)\end{array}$ & $\begin{array}{l}34.0 \\
(4.8)\end{array}$ & $\begin{array}{l}35.7 \\
(4.4)\end{array}$ & .413 & 0.018 & $-1.62 ; 0.68$ & .481 & 0.014 & $\begin{array}{c}-2.41 \\
1.16\end{array}$ \\
\hline
\end{tabular}

Note: EDE-Q Eating Disorder Examination-Questionnaire; TFEQ Three-Factor Eating Questionnaire; BMI Body Mass Index; CI confidence intervals

Means (SD)

${ }^{a}$ Effect sizes (partial eta squares) of the differences at post assessment

${ }^{\mathrm{b}}$ Effect sizes (partial eta squares) of the differences at follow-up assessment

shape and weight concerns and for disinhibition and hunger were medium. Effect sizes for shape concern and hunger were still medium after six months of WLT but only TFEQ hunger approached significance $(\mathrm{F}(2,35)=3.8, \mathrm{p}=.060)$. There was no difference in change in BMI between groups.

A significant decrease with a large effect size was found for the BDI-II in the Internet program group at post evaluation, compared to the control group $(\mathrm{F}(2,37)=6.3, \mathrm{p}=.017)$. At follow-up the difference between groups only approached but did not reach significance $(\mathrm{F}(2,35)=4.0, \mathrm{p}=.052)$ and effect size was medium. SCL-90R GSI scores between groups approached but did not reach significance at post assessment $(\mathrm{F}(2,37)=3.0, \mathrm{p}=0.91)$, with a medium effect size. At followup evaluation, the effect size between groups for SCL-90R GSI was large and significant $(\mathrm{F}(2,35)=6.7, \mathrm{p}=.014)$. The Internet program group showed greater improvements in psychological health at follow-up than the control group. As illustrated in Table 3, after six months of Internet program, patients' quality of life progressed on all dimensions, with all IWQOL-Lite subscales exhibiting significant comparisons between groups and medium to large effect sizes, which remained at follow-up evaluation, except for the "sexual life" subscale. The IWQOL-Lite total score effect size between groups was significant and large after six months of Internet program $(\mathrm{F}(2,37)=14.2, \mathrm{p}=.001)$ and sustained after six months of WLT $(\mathrm{F}(2,35)=8.0, \mathrm{p}=.008)($ Fig. 3).

\section{Compliance}

Theoretically selected compliance indicators were the number of modules completed at post evaluation, the number of e-mails sent by participants and the number of days that the self-monitoring diary was completed. A multiple regression analysis was run with IWQOL-Lite total change score (between baseline and post evaluation) as the dependent variable and baseline IWQOL-Lite total score as a covariate. Only two predictors were significant in the model, which explained $49 \%$ of variance: the number of modules completed at post evaluation (Bêta $=0.874, \mathrm{t}=3.9, \mathrm{p}=.001$ ) and the number of e-mails sent by participants $(\mathrm{Bêta}=-0.710, \mathrm{t}=-3.2$, $\mathrm{p}=.005)$. IWQOL-Lite total score baseline value was not a predictor. This means that firstly there was no correlation between the quality of life experienced at baseline and its improvement at post evaluation. Secondly, higher quality of life was correlated with further progress with the Internet program modules and fewer e-mails written by participants to their coach. 
Table 3. Psychological Health and Quality of Life for the Internet Program and Control Groups at Baseline, Post and Follow-up Evaluations; p-values, Effect Sizes and Confidence Intervals for Differences between Groups

\begin{tabular}{|c|c|c|c|c|c|c|c|c|c|c|c|c|}
\hline & \multicolumn{2}{|c|}{$\begin{array}{c}\text { Baseline assess- } \\
\text { ment }\end{array}$} & \multicolumn{2}{|c|}{ Post assessment } & \multicolumn{2}{|c|}{$\begin{array}{c}\text { Follow-up assess- } \\
\text { ment }\end{array}$} & \multicolumn{3}{|c|}{ Post differences } & \multicolumn{3}{|c|}{ Follow-up differences } \\
\hline & $\begin{array}{c}\text { Internet } \\
\mathrm{n}=22\end{array}$ & $\begin{array}{c}\text { Control } \\
n=20\end{array}$ & $\begin{array}{c}\text { Internet } \\
\mathrm{n}=20\end{array}$ & $\begin{array}{c}\text { Control } \\
n=20\end{array}$ & $\begin{array}{c}\text { Internet } \\
n=20\end{array}$ & $\begin{array}{c}\text { Control } \\
n=18\end{array}$ & $\mathrm{p}$-value & $\mathrm{ES}^{\mathrm{a}}$ & $\begin{array}{c}\text { CI } \\
(95 \%)\end{array}$ & $\mathrm{p}$-value & $\mathrm{ES}^{\mathrm{b}}$ & CI $(95 \%)$ \\
\hline BDI-II & $\begin{array}{l}11.2 \\
(9.7)\end{array}$ & $\begin{array}{c}15.0 \\
(11.5)\end{array}$ & $\begin{array}{c}5.7 \\
(6.2)\end{array}$ & $\begin{array}{c}12.7 \\
(10.0)\end{array}$ & $\begin{array}{c}4.2 \\
(4.4)\end{array}$ & $\begin{array}{c}11.4 \\
(13.4)\end{array}$ & .017 & 0.146 & $\begin{array}{l}-9.48 \\
-1.01\end{array}$ & .052 & 0.103 & $\begin{array}{c}-12.16 \\
0.07\end{array}$ \\
\hline $\begin{array}{l}\text { IWQOL } \\
\text { physical } \\
\text { function }\end{array}$ & $\begin{array}{c}54.3 \\
(24.3)\end{array}$ & $\begin{array}{c}53.6 \\
(24.6)\end{array}$ & $\begin{array}{c}66.2 \\
(24.6)\end{array}$ & $\begin{array}{c}56.2 \\
(26.2)\end{array}$ & $\begin{array}{c}75.8 \\
(21.7)\end{array}$ & $\begin{array}{c}61.2 \\
(25.6)\end{array}$ & .039 & 0.110 & $\begin{array}{l}0.44 \\
16.50\end{array}$ & .010 & 0.174 & $\begin{array}{l}4.14 ; \\
28.70\end{array}$ \\
\hline $\begin{array}{l}\text { IWQOL self- } \\
\text { esteem }\end{array}$ & $\begin{array}{c}34.2 \\
(23.9)\end{array}$ & $\begin{array}{c}34.9 \\
(22.5)\end{array}$ & $\begin{array}{c}48.2 \\
(22.6)\end{array}$ & $\begin{array}{c}34.5 \\
(22.0)\end{array}$ & $\begin{array}{l}58.8 \\
(22.0)\end{array}$ & $\begin{array}{c}45.5 \\
(28.3)\end{array}$ & .013 & 0.157 & $\begin{array}{l}2.60 \\
20.25\end{array}$ & .063 & 0.095 & $\begin{array}{l}-0.08 \\
27.88\end{array}$ \\
\hline $\begin{array}{l}\text { IWQOL } \\
\text { public dis- } \\
\text { tress }\end{array}$ & $\begin{array}{c}82.7 \\
(15.4)\end{array}$ & $\begin{array}{c}79.0 \\
(21.4)\end{array}$ & $\begin{array}{c}90.5 \\
(11.9)\end{array}$ & $\begin{array}{c}79.0 \\
(17.7)\end{array}$ & $\begin{array}{l}93.3 \\
(7.3)\end{array}$ & $\begin{array}{c}81.6 \\
(19.3)\end{array}$ & .002 & 0.228 & $\begin{array}{l}3.60 \\
15.00\end{array}$ & .004 & 0.209 & $\begin{array}{l}3.91 \\
19.63\end{array}$ \\
\hline $\begin{array}{l}\text { IWQOL } \\
\text { work }\end{array}$ & $\begin{array}{c}85.1 \\
(17.2)\end{array}$ & $\begin{array}{c}76.8 \\
(22.8)\end{array}$ & $\begin{array}{c}92.0 \\
(11.5)\end{array}$ & $\begin{array}{c}72.2 \\
(26.1)\end{array}$ & $\begin{array}{l}95.8 \\
(6.4)\end{array}$ & $\begin{array}{c}76.6 \\
(28.1)\end{array}$ & .007 & 0.182 & $\begin{array}{c}4.27 \\
0.18\end{array}$ & .004 & 0.215 & $\begin{array}{l}6.18 \\
29.64\end{array}$ \\
\hline $\begin{array}{l}\text { IWQOL total } \\
\text { score }\end{array}$ & $\begin{array}{c}60.1 \\
(16.7)\end{array}$ & $\begin{array}{c}57.5 \\
(20.0)\end{array}$ & $\begin{array}{c}71.7 \\
(14.0)\end{array}$ & $\begin{array}{c}57.5 \\
(20.3)\end{array}$ & $\begin{array}{c}78.1 \\
(13.9)\end{array}$ & $\begin{array}{c}64.3 \\
(22.7)\end{array}$ & .001 & 0.277 & $\begin{array}{l}4.87 \\
16.21\end{array}$ & .008 & 0.187 & $\begin{array}{l}3.93 \\
23.78\end{array}$ \\
\hline
\end{tabular}

Note: BDI Beck Depression Inventory; SCL-90R GSI: Symptom Checklist-90-Revised Global Severity Index; IWQOL: Impact of Weight on Quality of Life; CI confidence intervals Means (SD)

${ }^{a}$ Effect sizes (partial eta square) of the differences at post assessment

${ }^{b}$ Effect sizes (partial eta square) of the differences at follow-up assessment

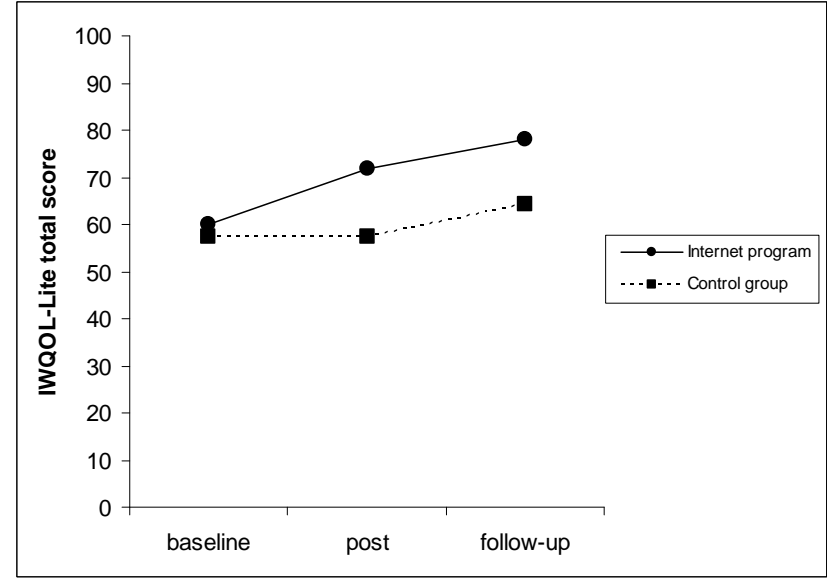

Fig. (3). Quality of life change for the Internet program and the control groups: baseline, after Internet program or waiting list (post) and after six months of WLT (follow-up).

\section{Interest in Trying the Internet Program}

Participants in the Internet program were asked about how they had become interested in the study. Several answers could be mentioned. The main reasons were:

- $36 \%$ thought that it was a good complement to WLT

- $32 \%$ wanted to begin something quickly
- $30 \%$ didn't want to miss out on any opportunity of getting better

- $23 \%$ reported having searched for an eating disorder treatment without finding anything suitable

- $21 \%$ said they wanted to try something other than a diet because they had already tried many of them without any change

- $16 \%$ thought that a psychotherapist could help them but were afraid of self-disclosure.

\section{Satisfaction with the Internet Program}

On a scale of 0 (not at all) to 10 (very), participants evaluated the self-monitoring diary exercise as useful $(\mathrm{M}=7.9, \mathrm{SD}=3.0)$. Diary feedback was not rated as positively $(\mathrm{M}=4.2, \mathrm{SD}=2.6)$. The Internet program was rated as 'easy to use' $(\mathrm{M}=8.6, \mathrm{SD}=1.9)$ and useful $(\mathrm{M}=8.1, \mathrm{SD}=1.9)$. E-mail contact with the coach was also considered valuable $(\mathrm{M}=7.9$, $\mathrm{SD}=2.2)$.

As shown in Table 4, all modules were estimated as 'easy to understand' with all means above 7 . The modules rated most difficult were 'meal planning' and 'cognitive restructuring', and those assessed most useful were 'selfmonitoring' and 'physical activity'. People most enjoyed the physical activity module together with the relapse prevention module (only rated by 3 participants). 
Table 4. Participants' Satisfaction with Each Module of the Internet Program

\begin{tabular}{|c|c|c|c|c|c|}
\hline Modules & $\mathbf{n}$ & Easy to understand & Difficult to do & Useful & Pleasant \\
\hline Binge triggers & 20 & $7.8(2.1)$ & $5.2(2.0)$ & $7.0(2.1)$ & $5.7(2.3)$ \\
\hline Meal plans & 18 & $7.7(2.1)$ & $5.8(2.5)$ & $6.7(2.0)$ & $5.6(2.4)$ \\
\hline Physical activity & 18 & $8.7(2.4)$ & $3.3(2.7)$ & $7.4(2.3)$ & $8.1(2.0)$ \\
\hline Problem-solving & 16 & $7.7(2.4)$ & $5.6(2.9)$ & $6.8(2.4)$ & $6.0(2.6)$ \\
\hline Assertiveness & 14 & $7.1(2.4)$ & $5.1(1.8)$ & $6.4(3.0)$ & $5.9(3.2)$ \\
\hline Automatic thoughts & 9 & $7.4(3.2)$ & $4.1(3.0)$ & $5.9(3.4)$ & $6.1(3.3)$ \\
\hline
\end{tabular}

Means (SD)

\section{DISCUSSION}

This study is among the first studies evaluating online self-help treatment programs for BED. An Internet CBTbased self-help treatment program was proposed for BED obese patients looking primarily for a weight loss treatment. Acceptance and satisfaction with the Internet delivery mode were high. Compared to the wait-listed group, the Internet program group showed a higher rate of binge eating abstinence, improvements on eating disorder scales, depression and quality of life. After a follow-up including six months of WLT for all patients, positive effects were sustained for psychological health and quality of life in the Internet program group.

\section{Acceptance}

The Internet program was offered to obese adult women seeking a weight loss treatment. Of 42 individuals to whom the program was offered, $23(55 \%)$ were interested. This is a surprisingly high number considering that these people were for the most part not searching for a psychological treatment for their eating disorder. Among the 22 persons included in the study, all exhibited symptoms of eating disorder, with $54.5 \%$ meeting full BED criteria. The Internet interface was not an obstacle in this age group. Participants from 21 to 70 years old, (with a mean of 44 years) were included. One 74year old woman was excluded. The Internet had already proved valuable for overweight adolescents with eating disorders [28]; in the present study it appeared to be equally acceptable for obese BED adults.

Only two people $(9 \%)$ dropped out during the Internet program. This is a high completion rate and may be explained by the fact that it was immediately followed by WLT. Even though it was emphasized that participants could withdraw from the Internet program without affecting their access to WLT, it is likely that they wanted to make a good impression on the team. But considering that a high rate of participants reached module 6 , it seems probable that there was also some interest in the program. Participants were en- couraged by their coaches to complete at least the first six modules, which were behavioral modules focusing directly on their eating problem. Not all participants were willing partake in further modules that were focused on issues that were less directly linked to their eating disorder, including those on assertiveness and cognitive restructuring.

Participants indicated a range of reasons for their interest in the Internet program including expectations that it would benefit them to begin treatment as soon as possible, and that it would complement their WLT. Some participants indicated that they were really suffering from their psychological difficulties but did not know how to access help. BED is still not well known amongst the general population and some of the participants were relieved to learn that they had a diagnosable condition with a recommended treatment plan.

User satisfaction was high. Participants rated the Internet program easy to use and useful, even if they did not lose weight during the course of the program. Participants particularly appreciated the self-monitoring exercise. They reported that self-monitoring diaries were useful as a framework to help structure their eating behavior. Participants indicated that they liked the module on physical activity most. The module provided tips, with easily achievable recommendations, and encouraged them to find new strategies for increasing their daily activity. This might have given them a greater sense of self-efficacy than modules on meal planning and strategies to prevent binges that were judged to be more difficult.

\section{Efficacy}

After six months of intervention, $45 \%$ of patients in the Internet program group were considered abstinent from binges over the past three months. This percentage is comparable to the percentage of abstinence observed with guided self-help books for BED with the less stringent criterion of no binge eating episodes for the last 28 days [19, 20]. At post evaluation, after six months of WLT, both groups reached the same result, with $55 \%$ of abstinent patients in each 
group. This is consistent with studies comparing behavioral weight loss treatment and CBT in the treatment of BED, indicating similar effects on binge eating in the short-term [51]. What is more, WLT in this study consisted of onsite motivational days, as well as individual follow-up and guidance on a range of topics: nutrition, physical activity, body image with art-therapy, including cognitive behavioral techniques [52]. However, shape concern, hunger and psychological health effect sizes were still medium to large at follow-up. Even if binge eating decreased in a similar way after six months of WLT in both groups, a larger change might have occurred in the Internet program group. A previous study indicated that CBT was more effective than behavioral weight loss treatment in eliminating binge eating at two-year follow-up [53]. A longer follow-up would be needed in this study to compare change in binge eating frequency following WLT between the Internet program and the control groups.

Consistent with the reduction of binge eating after the Internet program, medium effect sizes were found for disinhibition and hunger at post evaluation, indicating more control over eating. The significant and sustained medium effect size on 'susceptibility to hunger', which refers to perception of hunger and satiety, might have been enhanced by the mindfulness techniques, which have proved efficient in previous studies [54].

A large and significant effect for depression and a medium effect for psychological health were found in favour of the Internet program group. Depression is an important factor in BED obese patients, linked to poorer weight loss outcome and higher dropout rates [55]. Any improvements to depression levels may therefore facilitate weight loss in the long-term.

Quality of life was significantly enhanced by the Internet program and the effect was sustained over time in the domains of work, public distress, physical function and selfesteem. It is established that BED among obese individuals is associated with a lower quality of life, especially in these domains [10], even when controlling for depression and selfesteem [9]. This further highlights the importance of treating binge eating symptoms in this group in order to address their impaired quality of life [56]. CBT group treatment has been shown to improve quality of life for patients with BED [5]. The present study suggests that unlike WLT, CBT delivered by the Internet led to similar improvements.

\section{Compliance}

Multiple regression analysis showed a relationship between the module reached at post evaluation, the number of messages sent, and quality of life improvement. Firstly, the more modules that were accessed by participants, the more their quality of life improved. Completing the modules may have directly enhanced quality of life, or perhaps those with higher improvements of quality of life were more motivated to complete the modules. Secondly, less e-mails exchanged with the coach was correlated with higher quality of life scores. This could be seen as the participants needing less contact as their overall status improves. Contrary to a previous European study with an Internet self-help treatment program for bulimia nervosa [33], the number of days the selfmonitoring diary was completed was not correlated with outcome in this study.

\section{Limits}

There were several limitations to this first study of an Internet CBT-based BED self-help treatment program in an adult obese population. These results should be interpreted with caution because of the small sample size. Effect sizes suggest interesting findings but many effects failed to reach significance suggesting that this study was underpowered. In the absence of a longer follow-up, we can only hypothesize about the positive long-term effects of the Internet program. Particularly, a longer follow-up would provide more information on the specific effects of the Internet program on binge eating and eating disorder scales compared to a weight loss treatment. To recruit BED patients among obese people looking for a weight loss treatment was not an easy task. BED is often denied and weight loss is the primary and only goal. This was an innovative study which provided an Internet-based self-help treatment to a population who do not usually have the access or motivation to engage in such a program. This preliminary trial was controlled but not randomized. A randomized controlled trial with a larger sample is merited to test the significance and validity of the findings of this study. A larger number of subjects would also enable us to determine a profile of individuals who would better benefit from the BED Internet self-help treatment program.

\section{CONCLUSION}

A six-month Internet CBT-based self-help treatment program for BED was well-accepted by users and demonstrated promising results on binge eating, eating disorders key related factors, depression and quality of life, compared to a control group. What is more, significant improvements in psychological health and quality of life were recorded and maintained in the Internet program group after six months of WLT for all patients.

The results of this study suggest that the Internet is a valuable way of disseminating CBT for BED obese patients. A next step would be to include modules targeting weight loss in the Internet program and to evaluate its effectiveness on weight loss. The Internet program could be used during a waiting list for an obesity treatment or at any time in parallel with another treatment. Given that sustainable weight loss is predicted by abstinence from binge eating [57], it is imperative that binge eating be addressed in the long-term management of obesity.

\section{ACKNOWLEDGEMENTS}

This work was partially supported by funding from the Marie Curie Research Training Network INTACT (Individually tailored stepped care for women with eating disorders; MRTN-CT-2006-035988) and by the Hans Wilsdorf Foundation.

\section{DECLARATION OF INTEREST}

Tony Lam is director of NetUnion, a provider of health management software.

\section{REFERENCES}

[1] WHO, Obesity: Preventing and managing the global epidemic. Geneva: Author 2000.

[2] Greenberg I, Perna F, Kaplan M, Sullivan MA. Behavioral and psychological factors in the assessment and treatment of obesity surgery patients. Obes Res 2005; 13(2): 244-9. 
[3] Perri MG. The maintenance of treatment effects in the long-term management of obesity. Clinical Psychology: Sci Pract 1998; 5: 526-43.

[4] American Psychiatric Association, Diagnostic and statistical manual of mental disorders, 4th ed, Washington, DC: American Psychiatric Press 1994.

[5] Marchesini G, Natale S, Chierici S, et al. Effects of cognitivebehavioural therapy on health-related quality of life in obese subjects with and without binge eating disorder. Int $\mathrm{J}$ Obes Relat Metab Disord 2002; 26(9): 1261-7.

[6] de Zwaan M, Binge eating disorder and obesity. Int J Obes Relat Metab Disord 2001; 25 (Suppl 1): S51-5.

[7] de Zwaan M, Mitchell JE, Seim HC, et al. Eating related and general psychopathology in obese females with binge eating disorder. Int J Eat Disord 1994; 15(1): 43-52.

[8] Specker S, de Zwaan M, Raymond N, Mitchell J. Psychopathology in subgroups of obese women with and without binge eating disorder. Compr Psychiatry 1994; 35(3): 185-90.

[9] de Zwaan M, Mitchell JE, Howell LM, et al. Two measures of health-related quality of life in morbid obesity. Obes Res 2002; 10(11): 1143-51.

[10] Rieger E, Wilfley DE, Stein RI, Marino V, Crow SJ. A comparison of quality of life in obese individuals with and without binge eating disorder. Int J Eat Disord 2005; 37(3): 234-40.

[11] Blaine B, Rodman J. Responses to weight loss treatment among obese individuals with and without BED: a matched-study metaanalysis. Eat Weight Disord 2007; 12(2): 54-60.

[12] Striegel-Moore RH, Franko DL. Should binge eating disorder be included in the DSM-V? A critical review of the state of the evidence. Annu Rev Clin Psychol 2008; 4: 305-24.

[13] Wonderlich SA, Gordon KH, Mitchell JE, Crosby RD, Engel SG. The validity and clinical utility of binge eating disorder. Int $\mathrm{J}$ Eat Disord 2009; 42(8): 687-705.

[14] Wilson GT, Sysko R. Frequency of binge eating episodes in bulimia nervosa and binge eating disorder: Diagnostic considerations. Int J Eat Disord 2009; 42(7): 603-10.

[15] Wolfe BE, Baker CW, Smith AT, Kelly-Weeder S. Validity and utility of the current definition of binge eating. Int $\mathrm{J}$ Eat Disord 2009; 42(8): 674-86.

[16] Striegel-Moore RH, Dohm FA, Solomon EE, et al. Subthreshold binge eating disorder. Int J Eat Disord 2000; 27(3): 270-8.

[17] Crow SJ, Agras SW, Halmi K, Mitchell JE, Kraemer HC. Full syndromal versus subthreshold anorexia nervosa, bulimia nervosa, and binge eating disorder: a multicenter study. Int J Eat Disord 2002; 32(3): 309-18.

[18] Brownley KA, Berkman ND, Sedway JA, Lohr KN, Bulik CM. Binge eating disorder treatment: a systematic review of randomized controlled trials. Int J Eat Disord 2007; 40(4): 337-48.

[19] Carter JC, Fairburn CG. Cognitive-behavioral self-help for binge eating disorder: a controlled effectiveness study. J Consult Clin Psychol 1998; 66(4): 616-23.

[20] Grilo CM, Masheb RM. A randomized controlled comparison of guided self-help cognitive behavioral therapy and behavioral weight loss for binge eating disorder. Behav Res Ther 2005; 43(11): 1509-25.

[21] Tate DF, Zabinski MF. Computer and Internet applications for psychological treatment: update for clinicians. J Clin Psychol 2004; 60(2): 209-20.

[22] Griffiths KM, Christensen H. Review of randomised controlled trials of internet interventions for mental disorders and related conditions. Clin Psychol 2004; 10: 16-29.

[23] Tate DF, Wing RR, Winett RA. Using Internet technology to deliver a behavioral weight loss program. JAMA 2001; 285(9): 11727 .

[24] Tate DF, Jackvony EH, Wing RR. Effects of Internet behavioral counseling on weight loss in adults at risk for type 2 diabetes: a randomized trial. JAMA 2003; 289(14): 1833-6.

[25] Tate DF, Jackvony EH, Wing RR. A randomized trial comparing human e-mail counseling, computer-automated tailored counseling, and no counseling in an Internet weight loss program. Arch Intern Med 2006; 166(15): 1620-5.

[26] Krukowski RA, West DS, Harvey-Berino J. Recent advances in internet-delivered, evidence-based weight control programs for adults. J Diabetes Sci Technol 2009; 3(1): 184-9.
[27] Harvey-Berino J, Pintauro S, Buzzell P, Gold EC. Effect of internet support on the long-term maintenance of weight loss. Obes Res 2004; 12(2): 320-9.

[28] Jones M, Luce KH, Osborne MI, et al. Randomized, controlled trial of an internet-facilitated intervention for reducing binge eating and overweight in adolescents. Pediatrics 2008; 121(3): 453-62.

[29] Carrard I, Rouget P, Fernandez-Aranda F, et al. Evaluation and deployment of evidence based patient self-management support program for Bulimia Nervosa. Int J Med Inform 2006; 75(1): 1019.

[30] Pretorius N, Arcelus J, Beecham J, et al. Cognitive-behavioural therapy for adolescents with bulimic symptomatology: the acceptability and effectiveness of internet-based delivery. Behav Res Ther 2009; 47(9): 729-36.

[31] Fernandez-Aranda F, Nunez A, Martinez C, et al. Internet-based cognitive-behavioral therapy for bulimia nervosa: a controlled study. Cyberpsychol Behav 2009; 12(1): 37-41.

[32] Nevonen L, Mark M, Levin B, Lindstrom M, Paulson-Karlsson G. Evaluation of a new Internet-based self-help guide for patients with bulimic symptoms in Sweden. Nord J Psychiatry 2006; 60(6): 4638.

[33] Carrard I, Fernandez-Aranda F, Lam T, et al. Evaluation of a guided Internet self-treatment program for bulimia nervosa in several European countries. Eur Eat Disord Rev, doi: 10.1002/erv.1043.

[34] Hudson JI, Hiripi E, Pope HG Jr, Kessler RC. The prevalence and correlates of eating disorders in the National Comorbidity Survey Replication. Biol Psychiatry 2007; 61(3): 348-58.

[35] Fairburn CG. Overcoming binge-eating., New York, NY: The Guilford Press 1995.

[36] Jacobson E. Progressive relaxation. 2nd ed. Chicago: University of Chicago Press 1938.

[37] de Man Lapidoth J, Ghaderi A, Halvarsson-Edlund K, Norring C. Psychometric properties of the Eating Disorders in Obesity questionnaire: validating against the Eating Disorder Examination interview. Eat Weight Disord 2007; 12(4): 168-75.

[38] Carrard I, Crépin C. Troubles du comportement alimentaire et obésité (TAO). unpublished 2007.

[39] Fairburn CG, Beglin SJ. Assessment of eating disorders: interview or self-report questionnaire? Int J Eat Disord 1994; 16(4): 363-70.

[40] Mobbs O, Van der Linden M. Traduction française du questionnaire sur l'alimentation (Eating Questionnaire, EDE-Q). unpublished 2006.

[41] Stunkard AJ, Messick S. The three-factor eating questionnaire to measure dietary restraint, disinhibition and hunger. J Psychosom Res 1985; 29(1): 71-83.

[42] Lluch A. Identification des conduites alimentaires par approches nutritionnelles et psychométriques: implications thérapeutiques et préventives dans l'obésité humaine. Thesis, Université Henri Poincaré: Nancy 1995.

[43] Grilo CM, Masheb RM, Wilson GT. A comparison of different methods for assessing the features of eating disorders in patients with binge eating disorder. J Consult Clin Psychol 2001; 69(2): 317-22.

[44] Foster GD, Wadden TA, Swain RM, et al. The Eating Inventory in obese women: clinical correlates and relationship to weight loss. Int J Obes Relat Metab Disord 1998; 22(8): 778-85.

[45] Beck AT, Steer RA, Brown GK. BDI II, inventaire de dépression de Beck. $2^{\text {nd }}$ ed.; Paris: Editions du Centre de Psychologie Appliquée 1996.

[46] Derogatis LR. SCL-90-R (revised) Version manual I: Clinical Psychometrics Research Unit - John Hopkins University School of Medicine 1977.

[47] Guelfi JD, Dreyfus JF. La symptom check-list SCL-90R, in L'évaluation clinique standardisée en psychiatrie. Tome 1, J.D. Guelfi, Ed. Editions médicales Pierre Fabre: Boulogne, 1997.

[48] Kolotkin RL, Crosby RD, Kosloski KD, Williams GR. Development of a brief measure to assess quality of life in obesity. Obes Res 2001; 9(2): 102-11.

[49] Kolotkin RL. Questionnaire sur la qualité de vie liée à la santé (IWQOL-Lite - French). Durham, NC: Duke University Medical Center 2000.

[50] Cohen J, Cohen P, West SG, Aiken LS. Applied multiple regression/correlation analysis for the behavioral science. $3^{\text {rd }}$ ed. Mahwah, NJ: Lawrence Erlbaum, 2003. 
[51] Stunkard AJ, Allison KC. Binge eating disorder: disorder or marker? Int J Eat Disord 2003; 34 Suppl: S107-16.

[52] Buclin-Thiebaud S, Pataky Z, Bruchez V, Golay A. New psychopedagogic approach to obesity treatment: A 5-year follow-up. Patient Educ Couns 2010; 79(3): 333-7.

[53] Wilson GT, Wilfley DE, Agras WS, Bryson SW. Psychological treatments of binge eating disorder. Arch Gen Psychiatry 2010; 67(1): 94-101.

[54] Smith BW, Shelley BM, Leahigh L, Vanleit B. A preliminary study of the effects of a modified mindfulness intervention on binge eating. Complement Health Pract Rev 2006; 11: 133-43
Pagoto S, Bodenlos JS, Kantor L, et al. Association of major depression and binge eating disorder with weight loss in a clinical setting. Obesity (Silver Spring) 2007; 15(11): 2557-9.

[56] Marchesini G, Solaroli E, Baraldi L, et al. Health-related quality of life in obesity: the role of eating behaviour. Diabetes Nutr Metab 2000; 13(3): 156-64.

[57] Wonderlich SA, de Zwaan M, Mitchell JE, Peterson C, Crow S. Psychological and dietary treatments of binge eating disorder: conceptual implications. Int J Eat Disord 2003; 34 Suppl: S58-73.

Received: March 15, 2009

Revised: July 14, 2010

Accepted: July 14, 2010

(C) Carrard et al.; Licensee Bentham Open.

This is an open access article licensed under the terms of the Creative Commons Attribution Non-Commercial License (http://creativecommons.org/licenses/by-nc/3.0/) which permits unrestricted, non-commercial use, distribution and reproduction in any medium, provided the work is properly cited. 